\title{
Managing a Sustainable Transportation System: Exploring a Community's Attitude, Perception, and Behavior of the Morgantown Public Rapid Transit (PRT)
}

\author{
Vishakha Maskey ${ }^{1}$, Michael P. Strager ${ }^{2} \&$ Claudia Bernasconi ${ }^{3}$ \\ ${ }^{1}$ Gary E. West College of Business, West Liberty University, West Liberty, USA \\ ${ }^{2}$ Division of Resource Management, West Virginia University, Morgantown, USA \\ ${ }^{3}$ School of Architecture, University of Detroit Mercy, USA \\ Correspondence: Vishakha Maskey, West Liberty University, CSC 123, Faculty Drive, West Liberty, WV 26074, \\ USA. E-mail: vmaskey@westliberty.edu
}

Received: November 22, 2012 Accepted: December 22, 2012 Online Published: February 26, 2013

doi:10.5539/jms.v3n2p56 URL: http://dx.doi.org/10.5539/jms.v3n2p56

\begin{abstract}
Automated transportation is an innovative and sustainable concept that works emission-free with fully-automated and driverless vehicles on a network of specially-built, elevated guide ways. These systems are also called Automated People Mover (APM) or Public Rapid Transit (PRT) and are considered to be a solution to many global and environmental problems related to the use of the automobile. These transportation systems claim to be clean, affordable and safe technology, and a smart urban planning solution to move away from America's dependence on foreign oil, the faltering auto industry, and the misuse of urban landscapes. One of the first APM systems has been operating since the 1970's at West Virginia University in Morgantown, West Virginia. In order to examine community's attitude, perception and individual characteristic that influence the use of the systems, a random intercept survey was conducted. Findings from correlation analysis and an ordered probit model suggest socio-demographic attributes associated with attitudes toward the system. The frequent users are characterized as having a higher level of educational attainment, and are primarily students. Findings explore underlying factors regarding commuting, crucial for transportation policies and practices for managing sustainable transportation systems in comparable urban settings.
\end{abstract}

Keywords: automated transportation systems, user preference surveys, ordered probit model

\section{Introduction}

A current global energy crisis, increased urban population, and increased urban sprawl have exponentially raised concerns among planners, policy makers and commuters. One of the many solutions to these problems is sustainable transportation, in a form of Automated Public Movers (APM). There are numerous APM systems in several U. S. metropolitan areas (e.g. Atlanta, Orlando, and Pittsburgh) and in other parts of the world (e.g. Zurich, Rome, Tokyo, and London). Some of the recently completed systems have been at Heathrow Airport in London; and in Uppsala, Sweden. In the U.S., developments of the additional systems have been proposed for the city of Ithaca, New York and San Jose, California. These systems do not require drivers as the vehicles are guided through a control system and employ smaller electric vehicles. The units serve a relatively limited number of passengers per ride and provide on-demand service with no intermediate stops. The Personal Rapid Transport (PRT) is a form of APM that has smaller cross-sections of guide ways, tighter turning radii, and smaller vehicles, which are considered to have a lower visual impact compared to other transit systems (Schweitzer, 2005). The PRT system in Morgantown, West Virginia, United States (U.S.) is part of a wider family of automated transportation systems that has operated since the 1970s and has been a successful icon to many planners, designers, engineers and policy makers in the field of transportation.

\subsection{Problem Statement}

In order to increase the development and success of similar future systems, information regarding the behavior and attitudes toward ridership is needed (Cottrell, 2006). Studies have confirmed that economic and demographic factors influence travel demand (Centrino \& McGlukin, 2009), and suggest that these aspects are important in 
transportation systems planning, design and operation (Goulias, 2003). Information related to user demographics, behavior and attitudes toward the existing systems can be instrumental in guiding future systems. Moreover, transportation behavior also assists in forecasting future travel demand, evaluating the effectiveness of policies, predicting the response to new technologies or services, and anticipating possible unintended consequences. Studies also show that an individual's travel behavior, attitudes, and personality are influenced by their socio-demographic characteristics (Redmond, 2000; Cao \& Mokhtarian, 2005; Kim et al., 2007). The Morgantown PRT system is one of the first APM systems worldwide, and has been an instrumental mode of transportation system in Morgantown, with dense, vibrant university population. Investigating the attitude, behavior and perception of this system is timely and crucial for future development of sustainable transportation systems.

\subsection{Research Objectives}

This study examines how socio-demographic characteristics influence the use of the system in order to develop strategies for better management, and improve designs of future expansion. In order to evaluate an individual's travel behavior, attitude, and demographic characteristics on PRT usage, survey information was used to analyze the public usage of the PRT in Morgantown, West Virginia.

\subsection{Basic Hypotheses}

It is hypothesized that particular individual attributes such as socio-demographic variables may influence usage, and if identified and better understood, can provide necessary information to create more acceptable transport systems.

The individual characteristics examined in the study that could influence PRT use were attitude, behavior, and demographics. The findings of this research aim to evaluate attitudinal and behavioral responses toward the Morgantown PRT system with respect to individual's socio-demography, and investigate relationships between personal characteristics and the degree of PRT use.

\section{Background}

In the current era of high energy demand, grid-connected vehicles, APMs such as the Morgantown PRT are considered to be an answer to energy constraints because of lower energy usage compared to other means of public transportation (Gilbert \&Perl, 2006). Such systems also limit traffic congestion by using dedicated guideways and are considered a less polluting alternative. In addition, PRT systems integrate well with other forms of transportation, are environmentally friendly, and support sustainable living (Lowson, 2003). In that context, travel behavior and attitudes toward PRT systems can advance the current understanding of transportation literature.

A review of PRT related research publications since 1964 by Cottrell (2006) indicates that a number of issues still remain unresolved. Some problems include the enhancement of systems with no available federal funding; the integration of urban design principles into PRT transportation systems planning; the minimizing of investment risks of new developments, and the need to resolve ongoing technical problems (Cottrell, 2005). PRT systems also face competition from the existing established transport modes and require research on operational systems (Cottrell, 2005). The changing dynamics of land use associated with large transportation structure implies the need to focus on the interaction of people with transportation as there is an intricate relationship between the population who live and work around the transportation system (Wolf, 2007). It has been noted that user behavior and attitudes are important for the success of a system and have not been widely studied in the literature (Wolf, 2007).

The attitude of individuals has been shown to be an influential factor in land use conversion (Erickson et al., 2002; Luzar \& Diagne, 1999). Such attitudes can be derived from individual behavior, favorable and unfavorable responses through survey methods (Dawes, 1972). In addition, individual attitudes, personality, lifestyle and prior experience are likely to influence travel consideration, and are influenced by socio -economic and demographic characteristics (Cao \&Mokhtarian, 2005). Individual attitudes toward public transportation are also influenced by socio-economic, cultural and biophysical interaction. Therefore, attitudes at the local scale can impact transit oriented policies and planning decisions.

The National Household Travel Survey of Virginia (VTM Connection, 2009) suggests that travel trends are dependent upon socio-economic factors. Public transportation constitutes only $2 \%$ of urban travel (Pucher \& Renee, 2003), and the majority of travel is dominated by private cars in the U.S. Studies suggest that the use of public transportation makes up 3.7\% of all work trips, while use of the automobile is the dominant choice (75.4\%) for work trip (Pucher \&Renee, 2003). These numbers demonstrate the weakness of alternative and sustainable transportation modes compared to the car mode. As early as 1988, Pucher (1988) reported on the discrepancy between US and Europe, and indicated that only $40 \%$ of overall trips took place in cars in Western Europe. The more recent US transportation landscape has been captured by several surveys. According to the U.S. Department 
of Transportation, in $201140 \%$ of urban trips in the US were within two miles; of those $90 \%$ took place in cars (Fastlane, 2011). In 2010, the National Household Travel Survey released the results of a 2009 survey, which reported that $84 \%$ of all trips in US took place in personal vehicles, and that overall $28 \%$ of trips were within 1 mile (VTM Connection, 2009).

Travel behavior varies among socio-demographic groups such as age, income, ethnicity, gender, and race (Pucher $\&$ Renee, 2003). Pucher and Renee (2003) also suggest that the poor and elderly are less mobile as compared to the general population. Commuting behavior is moreover explained by general travel-related attitudes, personality traits, lifestyle priorities, and socio-demographic characteristics (Ory et. al., 2004). Therefore, evaluating public perception, attitude and behavior, as well as demographic information is important for public policy related to automated transportation planning and development.

Individuals make choices based on their preferences for the benefits obtained by travel modes and the relative cost of trips (Crane, 1998). Preference also reflects attitudes and tastes that vary with respect to demographic and personal characteristics (Crane, 1998). While the Morgantown PRT system was built over thirty-eight years ago, there are several proposals and projects in progress throughout the world connected to the development of new automated systems and in particular personal rapid transportation systems (Knetwork, 2008). The PRT system is suitable for commuting short distances, repetitive use with high density population such as major business, shopping, industrial, recreational and tourist areas, universities, hospitals and other important buildings, airports, railway stations, bus depots, major arteries, and existing transit systems (Laporte et. al., 2000). Many urban planners, policy makers, and designers agree on the need for increased public automated transportation. Therefore, identifying human aspects of this form of transportation will assist to further sustainable lifestyle.

\subsection{Description of Morgantown PRT}

The Morgantown PRT system has successfully been in operation since 1975, and currently includes five stations, each with different design and landscape attributes, and tracks that are elevated, at-street level, and also depressed (Figure 1). The Morgantown PRT is a unique automated transportation system with 70 vehicles having the capacity to hold 20 people, 8 seating and 12 standing. The vehicles are powered by electric rails and have rubber tires. It provides on-demand service with no intermediate stops (Raney \&Young, 2004). The system is part of the West Virginia University (WVU) infrastructure, and is crucial in connecting two separate campuses as well as parts of town. It was the New Electric Railway Journal's pick for best overall people-mover in 1998 (Davis, 2003). Population growth and traffic congestion in the downtown area of Morgantown has increased the demand for the system, leading to a future expansion plan. A new extension of the PRT system is currently being planned to address the increased service demand due to student population growth at WVU.

A labor analysis using civilian labor force data of Monongalia County for 2011 indicates that the urban population of the Morgantown area is comprised of 29,660 residents and an additional 29,000 college students associated with WVU during Fall and Spring semester schedules. Of the ten largest employers in the county, Morgantown is home to eight of the top ten of which the WVU two campuses plus the University Hospital system dominate in the number of employees. The transportation importance of the PRT as a system targeting the working groups and students becomes evident when looking at the numbers of the student population in Morgantown. As early as the 1970s the city of Morgantown started to experience high levels of congestion. As confirmed by PRT personnel, the system currently serves up to 15,000 users per day, providing for a more sustainable alternative to the car mode, and helping avoid congestion between the two WVU campuses. Examples of strong local population groups linking the University and community together can be found in several other large land grant schools and towns throughout the United States. It is in theses contexts, as well as in airport settings or downtowns, that APMs find their applicability as alternative sustainable transportation means capable of rapidly moving dense crowds and lowering number of short urban car trips. The transferability of design and application of the Morgantown PRT to other cities has significant opportunities in planning.

Ridership of the Morgantown PRT system was assessed in the late 70s (Sterns \& Schaeffer, 1977; Elias, 1979). A technological upgrade of the system was addressed over time (Alberts, et al. 1996; Kangas \& Bates, 1997; Sulkin, 2005). In addition, architectural improvements and proposed modifications to the vehicle control system and their impacts on the performance and operations of the Morgantown PRT system have been identified (Young and DeVault, 2005). A threats and vulnerabilities comparison study of Morgantown's PRT system and the surface transportation system of Kansas State University concluded that the Morgantown PRT system mitigates security and safety issues (Muller, 2007). As suggested by Cottrell (2005), the personal rapid transportation literature might be improved by greater introspection and criticism from the current operational sites. More specifically, the 
examination of attitude, behavior and demography of Morgantown residents and users will enhance the knowledge base of APM system planning and policies.

\section{Methods}

Methods consist of survey design, administration, and data analyses.

\subsection{Survey Design and Administration}

A survey was developed by the researchers and was pre-tested among the faculty and students at the institution. The self-administered survey was randomly administered in classrooms, local public areas, and also presented to pedestrians on the streets of Morgantown. The survey was a research effort to capture demographics, preferences (for use) and attitudes of the general public (both users and non-users) toward the Morgantown PRT system. The questions were related to the choice of transportation mode, and number of trips taken using the PRT, as well as user's attitudes toward various PRT attributes. In addition, demographic information was also collected in the survey. The explanatory variables observed in this analysis consisted of attitudinal and behavior responses, and demographic information of the respondents.

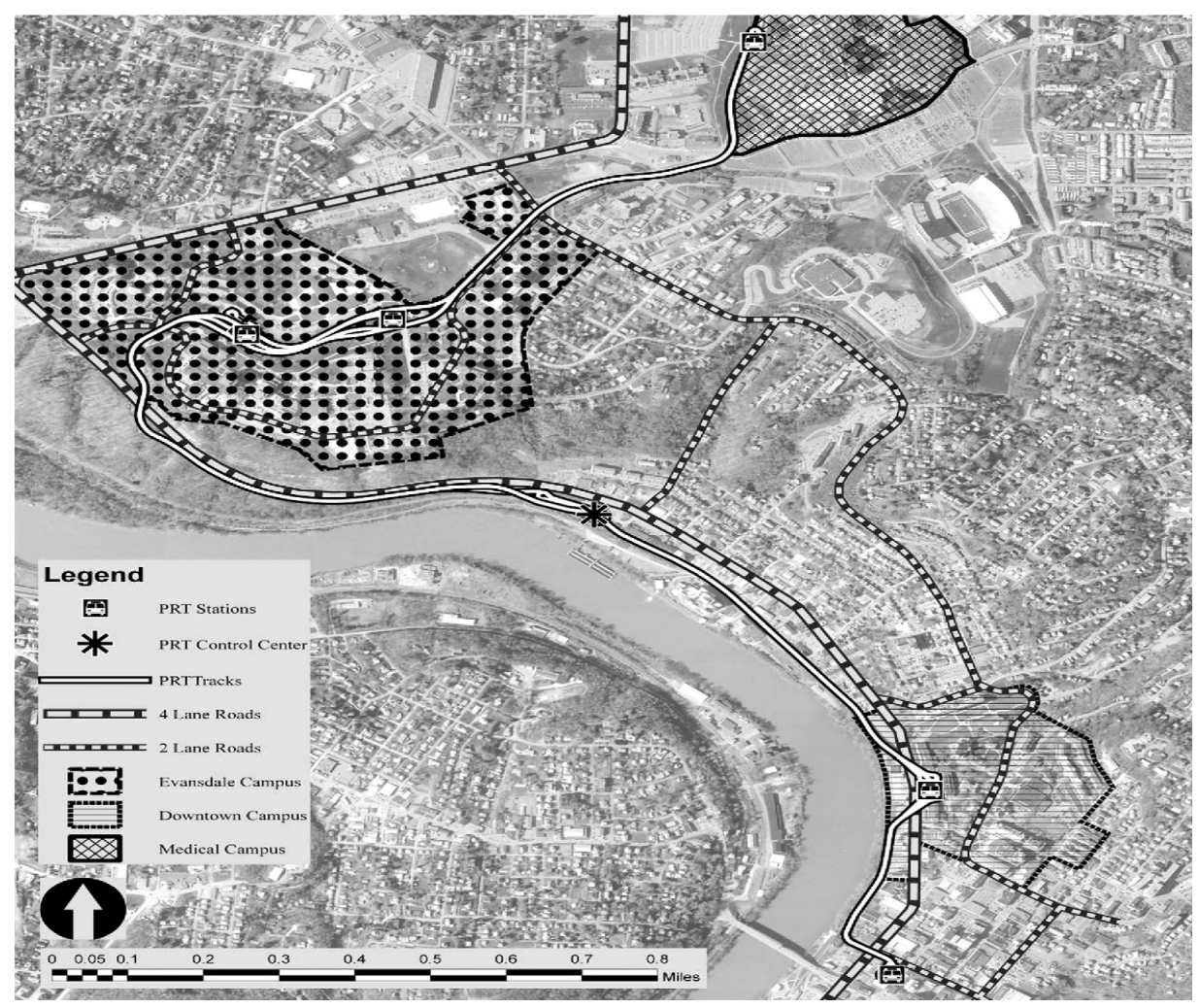

Figure 1. Location of map of the Morgantown PRT (from Bernasconi et al., 2009)

\subsection{Data Analyses}

The statistical evaluation methods included both correlation and regression analysis. The correlation analysis was chosen to suggest the statistical significance, direction and magnitude of the relationship between two variables (Cohen \&Cohen, 1983). A bivariate correlation analysis was utilized to understand and explain the nature of the relationship between individual characteristics and their attitude and behavior towards the PRT system.

Discrete choice models have been used in transportation modeling due to their relevance in policy making, capacity of integrated modeling, and market segmentation (Walker, 2005). These models can be employed for demand forecasting as a function of a system's attributes and pricing structure (Laporte et. al., 2000). Bierlaire (1998) proposes a model classification under four headings based on the decision maker's characteristics, the transportation choices available, their attributes, and the decision rules.

In this study, the statistical model is based on the assumption that the probability of individuals choosing a given option is a function of their socioeconomic and relative attractiveness of the option (de Panha Sanches \&Serra de 
Arrura, 2002). Discrete choice models allow for theoretically sound measures of demand elasticity, willingness to pay, and consumer benefits (Walker, 2005). The model also allows the capture of the individual attributes, such as demographic variables, behavior and attitude variables.

\subsection{Regression Analyses}

An ordered probit model assessed the relationship between respondent's characteristics and the degree of PRT use given the ordinal nature of the dependent variable. Ordered discrete alternatives such as the number of trips taken by individuals represent the choice as the outcome of a sequence of binary decisions, each one consisting of the decision to whether accept the current value or take an additional value (Ben-Akiva \&Lerman, 1985). The concept of utility is used to represent the attractiveness of the PRT system that initiates increased use of the system. An ordered probit model has been used in categorical analysis such as behavioral analysis, level of participation and severity analysis, where the dependent variable is an ordered ranking under normality assumption (Ronning $\&$ Kukuk, 1996). Therefore, an ordered probit model is utilized to determine factors that influence the probability of number of trips taken in PRT.

The empirical model can be expressed as:

$\mathrm{Uqj}=\beta 1+\beta \mathrm{Xj}+\alpha \mathrm{Xq}$ where,

Uqi $=$ utility of degree of PRT use for the individual $\mathrm{j} ; \beta 1=$ constant;

$\beta, \alpha=$ coefficient of variable;

$\mathrm{Xj}=$ variables representing demographic information;

$\mathrm{Xq}=$ variable representing attitude and behavior responses.

The coefficient of variable represents the influence of each demographic and behavior and attitude responses on the degree of PRT use (Table 1). In this case, the dependent variable is the degree of PRT use, which is represented as the number of PRT trips, where $0=$ none, 1-4 trips $=1,5-8$ trips $=2$, and more than 8 trips $=3$.

Table 1. Description of the variables

\begin{tabular}{|c|c|c|}
\hline Variable name & Description & Code \\
\hline Convenience & $\begin{array}{l}\text { Belief that PRT reduces } \\
\text { transportation problem and } \\
\text { increases convenient travel. }\end{array}$ & $\begin{array}{l}1=\text { strongly agree, agree, } 0= \\
\text { otherwise }\end{array}$ \\
\hline Car Appearance & $\begin{array}{l}\text { Belief that PRT car appearance is } \\
\text { appealing }\end{array}$ & $\begin{array}{l}1=\text { strongly agree, agree, } 0= \\
\text { otherwise }\end{array}$ \\
\hline Traffic Reduction & $\begin{array}{l}\text { Belief that PRT reduces traffic } \\
\text { problem in Morgantown }\end{array}$ & $\begin{array}{l}1=\text { strongly agree, agree, } 0= \\
\text { otherwise }\end{array}$ \\
\hline Student & Occupation & $\begin{array}{l}1=\text { WVU student, agree, } 0= \\
\text { otherwise }\end{array}$ \\
\hline Gender & Male or Female & $1=$ female, 0 otherwise \\
\hline Age & Age in category & $\begin{array}{l}18-19=1 ; 20-24=2 ; \\
25-34=3 ; 45-44=4 \\
45-54=5 ; 55-64=6 \\
65-74=7\end{array}$ \\
\hline Education & $\begin{array}{l}\text { Dummy variable for level of } \\
\text { education }\end{array}$ & $\begin{array}{l}1=\text { Bachelor's degree and higher, } 0 \\
\text { otherwise }\end{array}$ \\
\hline Period of Residence & $\begin{array}{l}\text { Period of residence in } \\
\text { Morgantown }\end{array}$ & $\begin{array}{l}1=\text { lived in Morgantown more } \\
\text { than } 2 \text { years, } 0=\text { otherwise }\end{array}$ \\
\hline
\end{tabular}

There may be other variables that may have influenced the PRT use. However, the error term is considered to be accounted for, among other things, the influence of omitted variables on the dependent variable (Barreto \&Howland, 2005).

\section{Results}

The results section is divided into summary statistics, correlation results and regression results. 


\subsection{Summary Statistics}

A sample demographic profile is presented in Table 2. Almost half (45\%) of respondents were between the age of 20-24, and age groups from $25-54$ are evenly represented at $16 \%, 12 \%$ and $12 \%$ respectively. Male and female respondents were also equally represented with $53 \%$ female and $47 \%$ male. Almost half ( $44 \%$ ) of the respondents had earned a bachelor's degree or higher and the majority (56\%) of respondents were students. More than half of the respondents lived in the Morgantown area for more than three years, and $65 \%$ were residing within the town, $51 \%$ employed at Morgantown and 2\% were visiting. Most of the respondents previously lived in a small to medium city.

Table 2. Respondent's demographic profile

\begin{tabular}{|c|c|c|}
\hline Variable & Responses count & $\%$ response \\
\hline \multicolumn{3}{|l|}{ Gender } \\
\hline Female & 95 & 53 \\
\hline Male & 85 & 47 \\
\hline \multicolumn{3}{|l|}{ Age } \\
\hline $18-19$ & 11 & 6 \\
\hline $20-24$ & 81 & 45 \\
\hline $25-34$ & 29 & 16 \\
\hline $45-44$ & 21 & 12 \\
\hline $45-54$ & 21 & 12 \\
\hline $55-64$ & 15 & 8 \\
\hline $65-74$ & 2 & 1 \\
\hline 75 years and over & 0 & 0 \\
\hline \multicolumn{3}{|l|}{ Education } \\
\hline $8^{\text {th }}$ grade or less & 0 & 0 \\
\hline $9^{\text {th }}, 10^{\text {th }}, 11^{\text {th }}$ grade & 1 & 0.6 \\
\hline High school graduate & 10 & 7 \\
\hline Some college, no degree & 79 & 45 \\
\hline Associate degree & 11 & 6 \\
\hline Bachelor's degree & 35 & 20 \\
\hline Master's degree & 24 & 14 \\
\hline Doctoral or professional degree & 18 & 10 \\
\hline \multicolumn{3}{|l|}{ Occupation } \\
\hline None & 1 & 0.6 \\
\hline Student & 99 & 56 \\
\hline Self employed & 5 & 3 \\
\hline Employed at WVU & 55 & 31 \\
\hline Retired & 1 & 0.6 \\
\hline Other & 17 & 10 \\
\hline \multicolumn{3}{|l|}{ Size of the community lived } \\
\hline Rural & 25 & 14 \\
\hline Small town & 40 & 22 \\
\hline Small to medium city & 86 & 48 \\
\hline Large city & 29 & 16 \\
\hline
\end{tabular}


Period of Residence in Morgantown

Less than one year

844

At least one year but less than two years

$21 \quad 12$

At least two years but less than three years

$26 \quad 14$

At least three years but less than five years

$39-22$

Five years or more

86

48

Purpose of being in Morgantown

Visiting

Working

Living

$\begin{array}{ll}4 & 2 \\ 92 & 51 \\ 117 & 65\end{array}$

A summary of respondent's behavior and attitude is presented in table 3. In terms of attitude and behavior of the respondents, $49 \%$ of the respondents were undecided on the belief that PRT reduced transportation problems. The appearance of PRT stations and cars also had mixed responses. Interestingly, the majority of respondents believed that the PRT was a convenient mode of transportation. However, only $7 \%$ used the PRT as their primary mode of transportation. Survey results indicated that the automobile $(61 \%)$ was the preferred mode of transportation. Surprisingly, the majority of respondents $(62 \%)$ stated that they have never used the PRT system.

Table 3. Respondent's attitude and behavior profile

\begin{tabular}{lll}
\hline Variable & Response count & Response \% \\
\hline PRT helps reduce transportation problems & 3 & 2 \\
Strongly agree & 54 & 30 \\
Agree & 89 & 49 \\
Undecided & 17 & 9 \\
Disagree & 16 & 9 \\
Strongly disagree & & \\
The appearance of the PRT car is pleasing & 24 & 13 \\
Strongly agree & 74 & 41 \\
Agree & 33 & 18 \\
Undecided & 38 & 21 \\
Disagree & 11 & 6 \\
Strongly disagree & & 3 \\
\hline The appearance of PRT station is pleasing & 6 & 31 \\
Strongly agree & 56 & 19 \\
Agree & 34 & 38 \\
Undecided & 68 & 8 \\
Disagree & 15 & 20 \\
Strongly disagree & 33 & 44 \\
\hline PRT system is convenient mode of transportation & 36 & 13 \\
Strongly agree & 80 & 4 \\
Agree & 23 & \\
Undecided & 33 \\
Disagree & & \\
Strongly disagree & & \\
\hline & & \\
& & \\
& &
\end{tabular}




\begin{tabular}{lll}
\hline Most important mode of transportation & & 28 \\
Walking & 50 & 2 \\
Bicycle & 3 & 2 \\
Bus & 4 & 7 \\
PRT & 13 & 61 \\
Car & 109 & 62 \\
\hline Number of trips taken in the PRT & 110 & 24 \\
None & 43 & 9 \\
$1-4$ trips & 16 & 6 \\
$5-8$ trips & 10 & 90 \\
More than 8 trips & & 7 \\
\hline Current residence & 161 & 3 \\
Morgantown & 13 & \\
Other location in West Virginia & 5 & \\
Other state & & \\
\hline
\end{tabular}

\subsection{Correlation Results}

Table 4 presents the results of the correlation analysis. The age variable was not used in the analysis since student population represented half of the sample. The analysis of binary correlation between demographic and attitudinal variables reveals that students and WVU employees share dissimilar attitudes toward the system. Students have a negative perception toward the station appearance, car appearance and do not believe that PRT is a convenient mode of transportation and reduces traffic problems. On the other hand, WVU employees have a positive attitude and perception toward the system's appearance and at the same time believed that it is a convenient mode of transportation and reduces traffic problems. Respondents with an attained education level higher than bachelor's degree and above also had a positive and significant relationship with the belief that PRT cars were appealing, and that the system reduced traffic congestion. An interesting finding is that residents who lived in Morgantown for longer periods of time had an inverse relationship with the PRT use but believed that the stations and cars were appealing and that the PRT did reduce traffic problems and was a convenient mode of transportation.

Table 4. Correlation analysis of demographic and attitude variable

\begin{tabular}{llllll}
\hline Demographic Variable & $\begin{array}{l}\text { Car } \\
\text { appearance }\end{array}$ & $\begin{array}{l}\text { Station } \\
\text { appearance }\end{array}$ & $\begin{array}{l}\text { Traffic } \\
\text { Reduction }\end{array}$ & Convenience & PRT use \\
\hline Student & $-0.41^{* * *}$ & $-0.33^{* * *}$ & $-0.17^{* *}$ & $-0.29^{* * *}$ & 0.07 \\
Education> bachelors & $0.21^{* * *}$ & 0.12 & $0.14^{*}$ & -0.30 & -0.02 \\
WVU employee & $0.37^{* * *}$ & $0.26^{* * *}$ & $0.17^{* *}$ & $0.21^{* * *}$ & -0.45 \\
Gender & 0.38 & 0.08 & -0.11 & -0.13 & -0.9 \\
Working in Morgantown & $0.23^{* * *}$ & -0.11 & $0.17^{* *}$ & 0.10 & 0.11 \\
Period of Residence in & $0.19^{* * *}$ & $0.16^{* *}$ & $0.28^{* * *}$ & 0.11 & $-0.14^{*}$ \\
Morgantown & & & & \\
Note: Correlation is significant at $* * *=1 \%, * *=5 \%$ and $*=10 \%$ respectively. & & \\
\hline
\end{tabular}

\subsection{Results from Regression Analysis}

The results from the ordered probit model are presented in table 5 . The dependent variable is number of trips $(0=$ none, $1-4$ trips $=1,5-8$ trips $=2$, and more than 8 trips $=3$ ). The results suggest that the probability of increased PRT use was positively influenced by the belief that PRT was a convenient mode of transportation. Specifically, education attainment of bachelor's degree and above increased positive attitude towards PRT. However, consistent with the correlation analysis result, a longer residency time in the Morgantown area was inversely related to the likelihood of increased PRT use. The results also revealed that the respondents' belief that the PRT car appearance was not appealing and resulted in less PRT use. In addition, being a student increased the probability of PRT trips 
taken. Age, gender, and the belief that the PRT reduced traffic problems were not explained by the model. This could be due to the lack in variation in age. Additionally, almost half of the respondents were not sure whether PRT reduced traffic problems.

Table 5. Ordered probit model

\begin{tabular}{lll}
\hline Variables & Estimates & P value \\
\hline Constant & $0.85(0.69)$ & 0.222 \\
Convenient & $\mathbf{0 . 5 8}(0.23)$ & 0.012 \\
Car Appearance & $\mathbf{- 0 . 3 5}(0.20)$ & 0.089 \\
Traffic Reduction & $0.21(0.27)$ & 0.438 \\
Student & $\mathbf{0 . 7 2}(0.29)$ & 0.014 \\
Gender & $0.63(0.19)$ & 0.748 \\
Age & $-0.21(0.10)$ & 0.828 \\
Education & $\mathbf{0 . 1 3}(0.07)$ & 0.063 \\
Period of Residence & $\mathbf{- 0 . 2 2}(0.08)$ & 0.017 \\
$\mu_{1}$ & $\mathbf{0 . 8 8}(0.11)$ & 0.000 \\
$\mu_{2}$ & $\mathbf{1 . 5 1}(0.16)$ & 0.000 \\
$\chi^{2}(8 d f)$ & $\mathbf{3 8}$ & 0.000 \\
\hline
\end{tabular}

Note: Standard errors are in parentheses. Bold indicates a statistically significant parameter estimate at the 10 percent level or better.

A majority of explanatory variables in this study were binary variables, therefore, the marginal effect is computed as the difference in the estimated probabilities with the dummy variable equal to one and zero and other variables at their means (Greene, 2004). Table 6 represents the estimated marginal coefficients of the variables. The result shows how the marginal effect changes with the number of trips taken. The belief that the PRT is a convenient mode of transportation increases the number of trips. In addition, the belief that car appearance is pleasing reduces after increased trips. The actual percentages of marginal effects are not interpreted because this approach is not appropriate for dummy variables (Greene, 2004).

Table 6. Marginal effects of the ordered probit model

\begin{tabular}{lllll}
\hline Variable & No trips to PRT & $1-4$ trips & $5-8$ trips & more than 8 trips \\
\hline Convenient & $\mathbf{- 0 . 2 1}$ & $\mathbf{0 . 1 1}$ & $\mathbf{0 . 0 6}$ & $\mathbf{0 . 0 4}$ \\
Car Appearance & $\mathbf{0 . 1 3}$ & $\mathbf{- 0 . 0 6}$ & $\mathbf{- 0 . 0 4}$ & $\mathbf{- 0 . 0 3}$ \\
Traffic Reduction & -0.08 & 0.04 & 0.02 & 0.01 \\
Student & $\mathbf{- 0 . 2 6}$ & $\mathbf{0 . 1 3}$ & $\mathbf{0 . 0 8}$ & $\mathbf{0 . 0 5}$ \\
Gender & -0.02 & 0.00 & 0.00 & 0.00 \\
Age & 0.14 & -0.00 & 0.00 & -0.00 \\
Education & $\mathbf{- 0 . 0 5}$ & $\mathbf{0 . 0 2}$ & $\mathbf{0 . 0 1}$ & $\mathbf{0 . 0 1}$ \\
Period of Residence & $\mathbf{0 . 0 8}$ & $\mathbf{- 0 . 0 4}$ & $\mathbf{- 0 . 0 2}$ & $\mathbf{- 0 . 0 2}$ \\
\hline
\end{tabular}

The education level higher than a bachelor's degree increases the probability of trips by $2 \%$ for $1-4$ trips, and further $1 \%$ for more trips. A longer residence time in the Morgantown area results in $8 \%$ probability of no PRT trips but decreases that likelihood of taking the PRT by 4\%, 3\% and 2\% respectively with 1-4 trips, 5-8 trips and more made. Being a student increases the probability of PRT trips by $13 \%$ for $1-4$ trips, $8 \%$ for $5-8$ trips and $5 \%$ for more than 8 trips.

\section{Conclusions}

The survey analyses suggest that throughout Morgantown, there is lower preference for the PRT compared to other modes of transportation such as the automobile. However, the PRT has been operating for a considerable time and both users and non-users overall had a positive perception of the system. The correlation analysis also suggests variation in the PRT attitude between users and non-users. Those who have attained advanced education, WVU employees, and individuals working in Morgantown reveal positive preferences toward the system compared to students. These individuals are also most likely to reside away from the PRT stations and may not use the system 
exclusively. However, the ordered probit model established that students were the most intensive users of the PRT system, which fulfills the goal of PRT establishment in the University town.

Since students are the primary users of the system, their concerns and attitude towards the system need to be addressed. The empirical findings suggest that the PRT system is indeed considered to be a convenient mode of transportation. This result is consistent with the idea of PRT advancement and expansion. However, a negative impact of PRT car appearance in the degree of use in Morgantown also provides some policy implications for ongoing maintenance and future expansion. Other studies have dealt with perception of appearance of automated people mover cars (e.g. Cook et al., 2004; Medus \& Lowson, 1999). A study by Bernasconi et al. (2009) also found that PRT maintenance levels impact users' and non-users' perception of PRT. According to the suggestions of respondents from the comments section in the survey, further enhancement or additional logistics to improve the ride such as parking (Park and Ride) to motivate residents in PRT use will also improve ridership. More enhancements toward the visual aesthetics and a more user-friendly station design were suggested improvement to the system.

In examining our findings from a sustainable transit perspective several contradictions appear. Close to half of the respondents did not agree that the PRT reduces traffic problems. This finding seems to be in stark contrast with facts on the PRT usage. Data provided by PRT personnel confirms that the system serves up to 15,000 users per day. It can be inferred that many of those trips would translate into additional car trips between campuses and additional traffic and parking problems in the town. Disagreement levels on PRT contribution to fewer traffic problems in our study might be a result of specificities in student perceptions of transportation alternatives, as students constitute the main user group and $56 \%$ of respondents. It can be inferred that students often want to own a car for the first time or more broadly to attain higher levels of independence. A study by Bayley et al. (2004) highlighted connections between perception of status and vehicles, and related perceptions of vehicle appearance to the desire of owning and driving a personal vehicle in young adults, and to desires for increased social status and independence.

Additionally, students did not seem to agree on the system's convenience. This result suggests that many of students preferred more traditional travel modes, such as personal vehicles. In fact, only $2 \%$ of respondents indicated they rely on local buses for everyday trips, while $61 \%$ of respondents indicated they rely on cars. Though this result confirms the predominant usage of car as primary transportation mode, which is typical of the great majority of US towns and cities, our study also indicates that perception of convenience of the PRT system increased with greater number of trips. In fact, though the main user group, students, had negative perceptions of convenience, overall those relying on the system for more trips were most likely to recognize its convenience. The increase in convenience perception was detected across categories (1-4 trips, 5-8 trips, and more than 8 trips per week). This result can suggest that those also relying on other transportation modes for their trips, versus the captive riders (i.e. those without other alternative transportation modes), seemed to benefit the most from the system in their opinion. More broadly this result also suggests that PRT, and APMs in general, can become a sustainable transportation alternative in dense urban contexts and has the potential to interface with other transportation modes in a convenient manner.

The study results suggest that the Morgantown PRT use is suitable in its urban location with the highly educated population and university environment that contains a large student population. The findings provide affirmation to implement such a system in similar locations. More specifically, issues addressed by this study suggest that the primary users of PRT system can provide information to guide future procurement. The current data analyses suggests that further investigation is needed in order to measure public preference for specific PRT improvements in the context of the more comprehensive urban transportation system of the town. In order to keep community informed, the website at WVU should address the specific changes and updates on PRT vehicles. Since most of the commute occurs during academic schedules and athletic events, a newsletter and website updates in addition to a mobile App development regarding the PRT status could increase effectiveness. Concurrent feedback to the administration from commuters through web or creating comment drop box would also improve system evaluation. Additional research based on current findings will be crucial to enhance public participation responses and to guide future system development.

\subsection{Limitation}

This is a case study of one of many APM systems worldwide and may not be relevant to newer systems. Most of the complaints from the PRT systems were due to older cars and congestion. One of the other limitations of this study was self -administered voluntary surveys. Respondents of the survey may not necessarily represent all PRT 
users in Morgantown. However, the findings do provide some insight on how sustainable transportation is still perceived as a positive attribute to the community and provides some sense of pride to the residents.

\section{References}

Barreto, H., \& Howland, F. M. (2005). Introductory Econometrics: Using Monte Carlo Simulations with Microsoft Excels. Cambridge University Press.

Bayley, M., Curtis, B., Lupton, K., \& Wright, C. (2004). Vehicle aesthetics and their impact on thepedestrian environment. Transportation Research Part D, 9, 437-450. http://dx.doi.org/10.1016/j.trd.2004.08.002

Ben-Akiva, M., \& Lerman, S. R. (1985). Discrete Choice Analysis: Theory and Application to Travel Demand. The MIT Press: Cambridge, Massachusetts.

Bernasconi, C., Strager, M. P., Maskey, V., \& Hasenmyer, M. (2009). Assessing the public preferences for design and environmental attributes of an urban automated transportation system. Landscape and Urban Planning, 90(3-4), 155-167. http://dx.doi.org/10.1016/j.landurbplan.2008.10.024

Brownstone, D. (2001). Discrete Choice Modeling for Transportation. In D. Hensher (Ed.), Travel Behaviour Research: The Leading Edge (pp. 97-124). Amsterdam: Pergamon.

Cao, X., \& Mokhtarian, P. L. (2005). How do individuals adapt their personal travel? A conceptual exploration of the consideration of travel-related strategies. Transport Policy, 12, 199-206.

Cohen, J., \& Cohen, P. (1983). Applied multiple regression/correlation analysis for the behavioral sciences (2nd ed.). Hillsdale, NJ:Erlbaum, Taylor \& Francis Group.

Contrino, H., \& Nancy, M. (2009). Demographics Matter: Travel Demand, Options, and Characteristics Among Minority Populations. Public Works Management and Policy, 13(4), 361-368. http://dx.doi.org/10.1177/1087724X09336223

Cook, C. V., Fereday, D., Lowson, M. V., \& Teychenne, R. T. (2004). Passenger response toa PRT system. Committee on Major Activity Circulation Systems (A1E11). Transportation Research Record 04-3058.

Cotrell, W. D. (2005). Critical Review of the Personal Rapid Transit Literature. Automated People Movers 2005, Moving to the Mainstream. Proceedings of the 10th International Conference on Automated People Movers, May 1-4, Orlando, Florida, USA. http://dx.doi.org/10.1061/40766(174)40

Cotrell, W. D. (2006). Moving driverless transit into the mainstream: Research issues and challenges. Transportation research record, 69-76. http://dx.doi.org/10.3141/1955-09

Crane, R. (1998). Travel by Design. Access, 12, 2-7.

Dawes, R. M. (1972). Fundamentals of Attitude Measurement. Wiley: New York.

da Penha Sanches \& Serra de Arruda, F. (2002). Incorporating Nonmotorized Modes in a Mode Choice Model. Transportation Research Record, 89-93.

Davis, J. (2003, January 26). PRT reaches milestone. West Virginia University Alumni Magazine.

Erickson, D. L., Ryan, R. L., \& De Young, R. (2002). Woodlots in the rural landscape: landowner motivations and management attitudes in a Michigan (USA) case study. Landscape Urban Planning, 58, 101-112. $\mathrm{http}: / / \mathrm{dx}$.doi.org/10.3141/1955-09

Fastlane, United States Department of Transportation. (2011). Are you ready for the 2 Mile Challenge? Retrieved from http://fastlane.dot.gov/2011/05/2-mile-challenge.html\#.UM-NHM1SyiU

Fabian, L. (2006). E-Cabs in our future. Transportation Planning, 31(1), 7-11.

Gilbert, R., \& Perl, A. (2007). Grid-connected vehicles as the core of future land-based transport systems. Energy Policy, 35, 3053-3060. http://dx.doi.org/10.1016/j.enpol.2006.11.002

Goulias, K. G. (2003). Transportation systems planning: methods and applications. CRC Press LLC.

Greene, W. H. (2004). Econometric analysis (4th ed.). Upper Saddle River, NJ: Prentice Hall.

Knetwork. (2008). Forget everything you thought you knew about mass transit. Retrieved March 20, 2008 from http://kinetic.seattle.wa.us/prt.html

Kim, S., Ulfarsson, G. F., \& Hennessy. J. T. (2007). Analysis of light rail rider travel behavior: Impacts of individual, built environment and crime characteristics on transit access. Transportation Research Part A, 41, 211-522. http://dx.doi.org/10.1016/j.tra.2006.11.001 
Laporte, G., Mesa, J. A., \& Ortega, F. A. (2000). Optimization methods for the planning of rapid transit systems. Invited Review. European Journal of Operational Research, 122, 1-10. http://dx.doi.org/10.1016/S0377-2217(99)00016-8

Lowson, M. (2003). A new approach to effective and sustainable urban transport. Transportation Research Board Annual Meeting, 03-2140.

Luzar, E. J., \& Diagne, A. (1999). Participation in the next generation of agriculture conservation programs: the role of environmental attitudes. Journal of Socio-Economics, 28, 335-349. http://dx.doi.org/10.1016/S1053-5357(99)00021-9

Medus, C. E., \& Lowson, M. V. (1999). Planning PRT networks: the case of ULTra (pp. 256-261). Paper Presented at ASCE APM Conference Copenhagen.

Muller, P. J. (2007). Personal Rapid Transit Safety and Security on University Campus. Transportation Research Board, 95-103. http://dx.doi.org/10.3141/2006-11

Ory, D. T., Mokhtarian, P. L., Redmond, L. S., Soloman, I., Collantes, G. O., \& Choo, S. (2004). When is Commuting Desirable to the Individual? Growth and Change, 35(3), 334-359. http://dx.doi.org/10.1111/j.1468-2257.2004.00252.x

Pucher, J. R., Evans, T., \& Wegner, J. (1998). Socio-economics and urban travel: Evidence from the 1995 NPTS. Transportation Quarterly, 52(3), 15-33.

Pucher, J. R., \& Renne, J. L. (2003). Socioeconomics of urban travel: Evidence from the 2001 NHTS. Transportation Quarterly, 57(3), 49-77.

Pucher, J. R. (1988). Urban Travel Behavior as an Outcome of Public Policy: The Example of Modal-Spilt in Western Europe and North America. Journal of the American Planning Association, 54(4), 49-77. http://dx.doi.org/10.1080/01944368808976677

Redmond, L. (2000). Identifying and Analyzing Travel-Related Attitudinal, Personality, and Lifestyle Clusters in the San Francisco Bay Area. Institute of Transportation Studies, University of California, Davis. Paper UCD-ITS-RR-00-08. Retrieved from http://repositories.cdlib.org/itsdavis/UCD-ITS-RR-00-08.

Ronning, G., \& Kukuk, M. (1996). Efficient estimation of ordered probit model. Journal of the American Statistical Association, 91(435), 1120-1129. http://dx.doi.org/10.1080/01621459.1996.10476982

Schweizer, J. (2005). The case for Personal Rapid Transit. Retrieved from www.advancedtransit.org

Sulkin, M. A. (1999). Personal Rapid Transit Deja Vu. Transportation Research Record, 1677, 58-63. http://dx.doi.org/10.3141/1677-07

Teychenne, R. (2005). Three Financial and Socio-Economic Assessments of a Personal Rapid Transit System. Automated People Movers 2005. Moving to the Mainstream. Proceedings of the 10th International Conference on Automated People MoversAmerican Society of Civil Engineers.

VTM Connection. (2009). Virginia National Travel Household Surve. Virginia's Transportation Modeling Newsletter, Summer (1-4).

Walker, J. L. (2005). Discrete Choice Models in Transportation: Proof of Concept. 84th Annual Meeting of the Transportation Research Board 84th Workshop 111: Innovative Travel Models Proof of Concept Washington, D.C.

Wolf, K. L. (2007). Transportation, Large Infrastructure, and Context in Urban Areas: A Review of Human-Scale Perception and Response, Paper 07-1842. Proceedings of the 86th Annual Meeting of the Transportation Research Board (January 21-25, 2007). Washington, D.C.: Transportation Research Board of the National Academies of Science.

Young, S. E., \& Vault, J. E. (2005). Incremental Improvements to the Morgantown PRT. Automated People Movers 2005. Moving to the Mainstream. Proceedings of the 10th International Conference on Automated People Movers American Society of Civil Engineers. http://dx.doi.org/10.1061/40766(174)43 